\title{
The incidence and predictors of poor glycemic control among adults with type 2 diabetes mellitus in ambulatory clinic of mettu karl referral hospital, southwestern, Ethiopia: a prospective cross sectional study
}

\author{
Gudisa Bereda* and Gemechis Bereda \\ SWAN diagnostic pharmaceutical importer, Addis Ababa, Ethiopia
}

\begin{abstract}
Background: Diabetes mellitus refers to a grouping of metabolic diseases involving prolonged hyperglycemia caused by the inadequate secretion of insulin, poor insulin action, or a combination of the two. Poor glycaemic control is a major public health problem among patients with type 2 diabetes mellitus.

Objective: To expose the incidence and predictors of poor glycemic control among adults with type 2 diabetes mellitus in ambulatory clinic of Mettu Karl Referral Hospital.

Methods: An institutional based prospective cross-sectional survey was carried out from April 23/2020 to June 24/2021. Data was collected through employing structured questioner, and then the collected data was cleared, coded and analyzed by statistical packages for social sciences 25.0 version statistical software. Descriptive statistics such as the frequency and percentage were used. Those variables with $\mathrm{p}$ - value less than 0.25 in bi-variable analysis were entered into multivariable analysis. A p-value of less than 0.05 was considered significant.

Results: A total of 122 patients with type 2 diabetes mellitus were included in this study. The overall incidence of poor glycemic control among type 2 diabetic patients was 60.7\%.Poor glycemic control was significantly associated with older age ( $\mathrm{AOR}=2.98,95 \% \mathrm{CI}: 1.089-2.023 ; \mathrm{P}=0.034)$, uneducated patients(AOR=5.075,95\%CI:1.957-3. 649; $\mathrm{p}=0.009)$,Glibenclamide+metformin drug regimen $(\mathrm{AOR}=3.95,95 \% \mathrm{CI}: 1.429-3.750 ; \mathrm{p}=0.018)$,Lowadherance $(\mathrm{AOR}=2.68,95 \% \mathrm{CI}: 1.764-4.928 ; \mathrm{p}=0.002), \mathrm{cigarette}$ smokers social habit (AOR=1.49,95\%CI:2.034-3.864; $\mathrm{p}=0.008$ ),patents who had comorbidities (AOR=2.5,95\%CI:1.967-5.497; $\mathrm{p}=0.028)$, and patients who had nephropathic complication of diabetes(AOR=6.45,95\%CI:3.071-17.632; $=0.005)$ were the significantly associated predictors of poor glycemic control.
\end{abstract}

Conclusion and recommendation: Our study investigated the prevalence of poor glycemic control among type 2 diabetic patients was high. About half of the patients were on anti-diabetic medication for between one to four years and slightly less than half of oral hypoglycemic agents were most prescribed drug regimen. Health care workers should have to advice the patients about life style modification and on how they take their medication.

\begin{abstract}
Abbreviations: ADA: American Diabetes Association; BMI: Body Mass Index; DM: Diabetes Mellitus; FPS: Fasting Plasma Sugar; HbAlc: Glycated Hemoglobin; HTN: Hypertension; MKRH: Mettu Karl Referral Hospital; SSA: Sub-Saharan Africa; T2DM: Type 2 diabetes mellitus; WHO: World Health Organization.
\end{abstract}

\section{Introduction}

Diabetes mellitus is a serious, chronic metabolic disorders that characterized by high sugar level either when the pancreas does not produce enough insulin, or when the body cannot effectively use insulin. Type 2 diabetes mellitus (T2DM) accounts about $90 \%$ of all diagnosed cases of diabetes among adults [1]. Globally,8.8\% (415 million) of adults suffered from diabetes in 2015,and it is estimated that 652 million people (10.4\%) will have diabetes by 2040.The World Health Organization (WHO) reported that high blood glucose level due to diabetes is the third highest risk factor for premature mortality after high blood pressure and tobacco use [2]. More than $77 \%$ of morbidity and $88 \%$ of mortality due to DM occur in low and middle-income countries. In Ethiopia, the prevalence of diabetes was $3.5 \%$ in 2011 [3]. Type 2 diabetes mellitus (T2DM) is the most common form of DM, accounting for more than $90 \%$ of cases. Control of diabetes is more than just taking medicine other aspects of self-management such as self-monitoring of blood glucose, dietary restrictions, regular foot care and ophthalmic examination have all been shown to markedly reduce the incidence and progression of diabetes complications [4]. The major risk factors in the development of T2DM are family history, obesity, race/ethnicity, age increment ( $\geq 40$ year), previous identified impaired fasting glucose or impaired glucose tolerance, hypertension (HTN), hyperlipidemia and history of gestational DM [5]. In Ethiopia, the prevalence of diabetes admission has increased from $1.9 \%$ in 1970 to $9.5 \%$ in 1999 of all medical admissions most importantly uncontrolled blood glucose due to non-compliance to anti-diabetic medications [6]. The American Diabetes Association (ADA) has designated HbA1c

${ }^{*}$ Correspondence to: Gudisa Bereda, SWAN diagnostic pharmaceutical importer, Addis Ababa, Ethiopia, Tel: +251919622717, E-mail: gudisabareda95@ gmail.com

Key words: type 2 diabetes mellitus, risk factors, poor glycemic control, ambulator $y$ clinic, mettu karl referral hospital, ethiopia

Received: June 10, 2021; Accepted: June 20, 2021; Published: June 30, 2021 
Bereda G (2021) The incidence and predictors of poor glycemic control among adults with type 2 diabetes mellitus in ambulatory clinic of mettu karl referral hospital, Southwestern, Ethiopia: a prospective cross sectional study

level of $<7 \%$ as a goal of optimal blood glucose control and the American Association of Clinical Endocrinologist has further recommended HbA1c level of $<6.5 \%$ [7]. Controlling the glycemic level is considered the main therapeutic intervention to prevent diabetes complications and further organ damage. Healthcare systems in sub-Saharan Africa (SSA) also vary widely [8]. There is poor health seeking behaviors in low resource countries because of inaccessible quality healthcare that increases the risk of DM complications. The management of DM is complex, and good glycemic control significantly reduces the risk of complications [9]. The goal of treatment for DM is to prevent mortality and complications by normalizing blood glucose level. But blood glucose level might be increased despite appropriate therapy resulting in complications, such as disturbances in fat metabolism, nerve damage, and eye disease [10].

Type 2 diabetes constitutes about $85-95 \%$ of all diabetes in highincome countries with a higher percentage in low and middle-income countries due to rapid socio- cultural changes, ageing populations, increasing urbanization, reduced physical activity and unhealthy lifestyle and behavioral patterns. It is a leading cause of blindness, end stage renal disease and stroke. These complications are two to five times more common among diabetic patients. Type 2 diabetes is associated with increased morbidity and mortality compared with the general population [11]. High glycemic control is difficult to achieve, and prior research has reported many factors as contributing to poor control among patients, including their age, gender, level of education, weight, smoking status, marital status, the duration of diabetes, the medications taken, and numerous other factors [12]. However, it has been proved difficult to confirm exactly which of these factors are most directly associated with poor glycemic control. The World Health Organization (WHO) reported that high blood glucose level due to diabetes is the third highest risk factor for premature mortality after high blood pressure and tobacco use [13]. Diabetes is attributed to $14.5 \%$ of all-cause mortality among adults, and half of these deaths occur in adults under the age of 60 years. Nonetheless, diabetic complications are a major cause of disability and reduced quality of life. The estimated total global health expenditure due to diabetes is $\$ 673$ billion in 2015, and it will reach $\$ 802$ billion in 2030 [14]. Previous findings in Ethiopia also reported that the rate of poor glycemic control was high [15], most importantly due to non-compliance to existing medications.32The prevalence of poor glycemic control is paramount. A study done in Malaysia [16], 2015 showed that $72 \%$ of patients had poor glycemic control, and two third of DM patients in Ethiopia [17] also had poor control. Previous studies assured that poor glycemic control correlated with enlarged risk of visual impairment, enlarged risk of kidney failure, and enlarged risk of cardiovascular disease [18]. This study will provide information for health-care providers and policymakers as a baseline for further study and determining the risk factors of poor glycemic control is important for its urgent management and further reduction of health-care costs related to the care needed.

\section{Materials and methods}

\section{Study area, design and period}

An institutional based prospective cross-sectional survey was conducted from April 23/2020 to June 24/2021, in the ambulatory clinic at Mettu Karl Referral Hospital, which located at $600 \mathrm{~km}$ from Addis Ababa.

\section{Study participants}

All type 2 diabetes patients who visited the ambulatory clinic of MKRH during the data collection period \& that fulfilled the inclusion criteria was target population. Those aged 18 years or older, Patients who were on anti-diabetic medication(s) treatment for at least 6 months, Patients with at least three consecutive blood glucose, Measurements for 3 months, and patients who consented to participate were included in the study. Newly diagnosed, very sick patients, and those with physical or mental handicaps, Patients with hearing problems and previously diagnosed psychiatric were excluded.

\section{Sample size calculation and sampling technique}

The sample size was determined by using the single population proportion formula: The sample size was determined based on "P" value which was taken from JUSH, Southwest Ethiopia, $\mathrm{P}=0.709$, or $70.9 \%$ $\mathrm{n}=((\mathrm{Za} / 2) 2 \mathrm{P}(1-\mathrm{P})) / \mathrm{d} 2, \mathrm{n}=$ sample size, $\mathrm{P}=$ prevalence of poor glycemic control, $\mathrm{d}=$ margin of sampling error tolerated, $\mathrm{z}=$ the standard normal value at confidence interval of $95 \% . n=(1.96) 2(1-0.709) \times(0.709) /$ $(0.05) 2=317$. Since the total number of type 2 diabetes mellitus patients was less than 10,000 ,reduction formula(correction formula) were applied as follow $n f=n /(1+(n / N)), n f=317 /(1+(317 / 170)=111$. When $10 \%$ contingency is added to minimize non response rate,then final sample size was found to be 122.Purposive sampling technique was used to recruit samples for the study in each day of the data collection process until the desired sample size was obtained.

\section{Study variables}

Dependent variable was poor glycemic control among adults with type 2 diabetes mellitus, and independent variable were Socio demographic factors (age, sex, educational status, monthly income, marital status, family size), Clinical characteristics (family histories of diabetes, the duration of disease, and self-reported comorbidities), Life style of patients'(smoking status, exercise per day and dietitians (which restricted their intakes of sugar, salt, and fat),Medications the patients were taking to manage their diabetes, and whether they self-monitored their blood glucose levels.

\section{Data extraction and procedure}

Data was collected from the medical cards to know their blood glucose level and patients were interviewed by using a semi-structured questionnaire developed by reviewing different literature's. The data collection format contained four parts. The first part of the questionnaire involved socio-demographic data on the participating patients' age, marital status, gender, residence, education level, employment status, and income. The second part concerned their clinical characteristics, including family histories of diabetes, the duration of disease, and selfreported comorbidities. The third part gathered lifestyle data on the patients' smoking status, whether they exercised regularly (i.e., whether they were involved in at least 30 minutes of exercise per day, at least 3 days per week), and whether they followed a set dietary plan approved by dietitians (which restricted their intakes of sugar, salt, and fat). The fourth and final part had questions on the medications the patients were taking to manage their diabetes, and whether they self-monitored their blood glucose levels. The weight of each patient were measured by using $\mathrm{BMI}=$ kilogram of the patients $(\mathrm{kg}) /$ height of patients $(\mathrm{m} 2)$. Based on the calculated BMI, the patients were divided into categories reflecting the World Health Organization (WHO)'s definitions: normal range (BMI $=18.5-24.9 \mathrm{~kg} / \mathrm{m} 2$, overweight $(\mathrm{BMI}=25-29.9 \mathrm{~kg} / \mathrm{m} 2$, and obese (BMI $\geq 30 \mathrm{~kg} / \mathrm{m} 2$. Glycemic control was based on American Diabetic Association (ADA) recommendation into two groups as good glycemic control with fasting blood glucose of $70-130 \mathrm{mg} / \mathrm{dL}$ and poor glycemic control with fasting blood glucose of $<70 \mathrm{mg} / \mathrm{dL}$ and $>130 \mathrm{mg} / \mathrm{dL}$. 
Bereda G (2021) The incidence and predictors of poor glycemic control among adults with type 2 diabetes mellitus in ambulatory clinic of mettu karl referral hospital, Southwestern, Ethiopia: a prospective cross sectional study

\section{Data processing and analysis}

The screened data was coded and analyzed through employing statistical packages for social sciences 25.0 version statistical software. Data are presented as the mean \pm standard deviation (SD) for continuous variables and proportions for categorical variables. Chi-square and bi variate logistic regression analysis was conducted to see the existence of odds association and select candidate variables with $\mathrm{P}$ value below 0.25 were considered to multivariable logistic regression. A 95\% CI and $\mathrm{p}$-value of $<0.05$ was considered to be statistically significant.

\section{Data quality assurance}

All steps in data collection and recording were closely monitored by the principal investigator and daily collected data was, recorded and compiled for the next day study. Finally, the data collected will be checked for completeness and consistency on daily basis

\section{Ethical considerations}

A formal letter was obtained from SWAN diagnostic pharmaceutical importer and official letter of co-operations was provided to mettu karl referral hospital prior to data collection. Patient consent was obtained prior to data collection and no personal identity was disclosed. The instruments and procedure were not cause any harm to the study subject. Thus, name and address of the patient was not recorded in data collection checklist.

\section{Operational Definitions}

Poor glycemic control was operationally defined if fasting blood glucose (FBG) level was above $130 \mathrm{mg} / \mathrm{dl}$.

\section{Results}

\section{Socio-demographic characteristics of the study participants}

A total of 122 type 2 diabetic patients were included in this study, of whom 67 (54.9\%) were male. The largest age group was $>40$ years

Table 1. Socio-demographic characteristics of the study of T2DM patients in Mettu Karl Referral Hospital, South-western, Ethiopia, 2021

\begin{tabular}{|c|c|c|c|}
\hline Variables & Category & Frequency & Percent \\
\hline \multirow{2}{*}{ Age } & $\leq 40$ years & 56 & 45.9 \\
\hline & $>40$ years & 66 & 54.1 \\
\hline \multirow{2}{*}{ Sex } & Male & 67 & 54.9 \\
\hline & Female & 55 & 45.1 \\
\hline \multirow{2}{*}{ Residency } & Urban & 50 & 41.0 \\
\hline & Rural & 72 & 59.0 \\
\hline \multirow{2}{*}{ Monthly income } & $\leq 500 \mathrm{ETB}$ & 79 & 64.8 \\
\hline & $>500 \mathrm{ETB}$ & 43 & 35.2 \\
\hline \multirow{2}{*}{ Marital status } & Unmarried & 43 & 35.2 \\
\hline & Married & 79 & 64.8 \\
\hline \multirow{4}{*}{ Educational status } & Uneducated & 45 & 36.9 \\
\hline & Primary & 39 & 32.0 \\
\hline & Secondary & 27 & 22.1 \\
\hline & Higher education & 11 & 9.0 \\
\hline \multirow{4}{*}{ Social habit } & Cigarette smokers & 38 & 31.1 \\
\hline & Alcohol drinker & 32 & 26.2 \\
\hline & Khat chewing & 22 & 18.0 \\
\hline & None & 30 & 24.6 \\
\hline \multirow{2}{*}{ Family history } & Yes & 45 & 36.9 \\
\hline & No & 77 & 63.1 \\
\hline \multirow{2}{*}{$\begin{array}{l}\text { Magnitude of poor glycemic } \\
\text { control }\end{array}$} & Yes & 74 & 60.7 \\
\hline & No & 48 & 393 \\
\hline
\end{tabular}

Table 2. Clinical characteristics and disease related variables among T2DM patients in Mettu Karl Referral Hospital, South-western, Ethiopia, 2021

\begin{tabular}{|c|c|c|c|}
\hline Variables & Category & Frequency & Percent \\
\hline \multirow{4}{*}{ Body mass index } & $<18.5 \mathrm{~kg} / \mathrm{m}^{2}$ & 18 & 14.8 \\
\hline & $18.5-24.9 \mathrm{~kg} / \mathrm{m}^{2}$ & 30 & 24.6 \\
\hline & $25-29.9 \mathrm{~kg} / \mathrm{m}^{2}$ & 42 & 34.4 \\
\hline & $\geq 30 \mathrm{~kg} / \mathrm{m}^{2}$ & 32 & 26.2 \\
\hline \multirow{2}{*}{ Fasting blood sugar } & $\leq 130 \mathrm{gm} / \mathrm{dl}$ & 33 & 27.0 \\
\hline & $>130 \mathrm{gm} / \mathrm{dl}$ & 89 & 73.0 \\
\hline \multirow{2}{*}{ Blood pressure } & $<140 / 90 \mathrm{mmHg}$ & 78 & 63.9 \\
\hline & $\geq 140 / 90 \mathrm{mmHg}$ & 44 & 36.1 \\
\hline \multirow{3}{*}{ Adherance } & Low & 56 & 45.9 \\
\hline & Moderate & 38 & 31.1 \\
\hline & High & 28 & 23.0 \\
\hline \multirow{2}{*}{ Co-morbidities } & Yes & 67 & 54.9 \\
\hline & No & 55 & 45.1 \\
\hline \multirow{5}{*}{ Complication } & Retinopathy & 16 & 13.1 \\
\hline & Cardiac complications & 17 & 13.9 \\
\hline & Nephropathy & 32 & 26.2 \\
\hline & Neuropathy & 12 & 9.8 \\
\hline & None & 45 & 36.9 \\
\hline \multirow{5}{*}{ Type of co-morbidities } & Hypertension & 55 & 45.1 \\
\hline & DKA & 5 & 4.1 \\
\hline & Renal disease & 21 & 17.2 \\
\hline & Peripheral neuropathy & 29 & 23.8 \\
\hline & Other & 12 & 9.8 \\
\hline \multirow{2}{*}{ Type of treatment } & Non-pharmacological & 33 & 27.0 \\
\hline & Pharmacological & 89 & 73.0 \\
\hline
\end{tabular}

which accounted for 66 (54.1\%). A majority 72(59.0\%)of patients were live in rural area and 79(64.8\%) were earn monthly income $\leq 500$ ETB. Majority 79(64.8\%) of patients were married and 43 (35.2\%) of patients were uneducated. Preponderance $38(31.1 \%)$ of patients had social habit which mostly accounted for cigarette smokers and 30(24.6\%) had now social habit. A majority 77(63.1\%) of patients had no family history. The overall incidence of poor glycemic control among type 2 diabetic patients was 74(60.7\%) (Table 1).

\section{Clinical characteristics and disease related characteristics}

A majority $42(34.4 \%)$ of the respondents were overweight. Great majority $89(73.0 \%)$ of participants had $>130 \mathrm{gm} / \mathrm{dl}$ fasting blood sugar and $78(63.9 \%)$ had $<140 / 90 \mathrm{mmHg}$ blood pressure. Regarding adherance 56(45.9\%),38(31.1\%),28 (23.0\%) was low, moderate and high respectively. Above half 67(54.9\%) of type 2 diabetic patients were had at least one comorbidities and 32(26.2\%) had nephropathy diabetic complication. Hypertension 55(45.1\%) was the most present comorbidities followed by renal disease $29(23.8 \%)$. Majority $89(73.0 \%)$ of study participants were pursue pharma cological only rather they use nonpharmacological treatment (Table 2).

\section{Medication related and lifestyle related characteristics}

About half $62(50.8 \%)$ of the patients were on anti-diabetic medication for between 1-4 years and slightly above one half 68(55.8\%) of oral hypoglycemic agents were most prescribed drug type. Metformin 41(33.6\%) was the mostly recommended drugs followed by Metformin and NPH insulin 34(27.9\%). Above half 77(63.1\%) of patients had $\leq 2$ number drugs they take and less than half 50(41.0\%) of patients had at least one concomitant medication. Enalapril 21(42\%) most concomitant medication administered followed by Enalapril+ASA $16(32 \%)$. Above half $66(54.1 \%)$ of patients had inadequate health diet 
Bereda G (2021) The incidence and predictors of poor glycemic control among adults with type 2 diabetes mellitus in ambulatory clinic of mettu karl referral hospital, Southwestern, Ethiopia: a prospective cross sectional study

Table 3. Medication related and life style related characteristics among T2DM patient $\mathrm{s}$ in Mettu Karl Referral Hospital, South-western, Ethiopia, 2021

\begin{tabular}{|c|c|c|c|}
\hline Variables & Category & Frequency & Percent \\
\hline \multirow{3}{*}{ Duration of treatment } & $1-4$ years & 62 & 50.8 \\
\hline & $5-10$ years & 43 & 35.2 \\
\hline & $>10$ years & 17 & 13.9 \\
\hline \multirow{2}{*}{ Drug regimen } & Oral hypoglycemic agents & 87 & 71.3 \\
\hline & Oral hypoglycemic agents + Insulin & 35 & 28.7 \\
\hline \multirow{5}{*}{ Type of DM drugs } & Metformin & 41 & 33.6 \\
\hline & Glibenclamide and metformin & 19 & 15.6 \\
\hline & Glibenclamide & 17 & 13.9 \\
\hline & Metformin and NPH insulin & 34 & 27.9 \\
\hline & Metformin+Glibenclamide+ insulin & 11 & 9.0 \\
\hline \multirow{2}{*}{$\begin{array}{l}\text { Numbers of drugs } \\
\text { tak en }\end{array}$} & $\leq 2$ drugs & 77 & 63.1 \\
\hline & $>2$ drugs & 45 & 36.9 \\
\hline \multirow{2}{*}{$\begin{array}{l}\text { Concomitant medicat } \\
\text { ion }\end{array}$} & Yes & 50 & 41.0 \\
\hline & No & 72 & 59.0 \\
\hline \multirow{4}{*}{$\begin{array}{l}\text { Type of concomitant } \\
\text { medication }\end{array}$} & Enalapril & 21 & 42.0 \\
\hline & Enalapril + ASA & 16 & 32.0 \\
\hline & Enalapril + ASA + atenolol & 9 & 18.0 \\
\hline & Enalapril+ASA+hydrochlorothiazide & 4 & 8.0 \\
\hline \multirow{2}{*}{ Health diet } & Adequate & 56 & 45.9 \\
\hline & Inadequate & 66 & 54.1 \\
\hline \multirow{2}{*}{ Physical exercise } & Yes & 43 & 35.2 \\
\hline & No & 79 & 64.8 \\
\hline \multirow{2}{*}{ Foot care } & Yes & 27 & 22.1 \\
\hline & No & 95 & 77.9 \\
\hline \multirow{2}{*}{$\begin{array}{l}\text { Self monitoring bloo } \\
\text { d glucose }\end{array}$} & Yes & 35 & 28.7 \\
\hline & No & 87 & 71.3 \\
\hline
\end{tabular}

and 79(64.8\%) hadn't do physical exercise. A majority 95 (77.9\%) of participants had not care their foot and $87(71.3 \%)$ had not have selfmonitoring blood glucose (Table 3).

Logistic regression analysis of the association between independent variables and poor glycemic control among T2DM

The relative odds of poor glycemic control was 2.98-times $(\mathrm{AOR}=2.98,95 \% \mathrm{CI}=1.089-2.023, \mathrm{P}=0.034)$ higher among patients in the age $\leq 40$ years compared to the ages of greater than 40 years. Regarding educational status uneducated patients were 1.75 more likely had poor glycemic control(AOR=1.75,95\% $\mathrm{CI}=1.957-3.649, \mathrm{P}=0.009)$ than primary, secondary and higher educational status. Patients who take Glibenclamide and metformin drug regimen were 3.95 more likely had poor glycemic control (AOR=3.95,95\%CI=1.967-9.645, $\mathrm{P}=0.018$ ) than those who taken others regimen. Low adherance were 2.68 more likely had poor glycemic control (AOR=2.68,95\% $\mathrm{CI}=1.967-9.645, \mathrm{P}=0.002)$ than moderate and high adherance. Patients who whose cigarette smokers social habit were 1.49 more likely had poor glycemic control $(\mathrm{AOR}=1.49,95 \% \mathrm{CI}=1.967-9.645, \mathrm{P}=0.008)$ than those who had others social habit. Patents who had comorbidities were
2.5 more likely have poor glycemic control $(\mathrm{AOR}=2.5,95 \% \mathrm{CI}=1.967-$ $5.497, \mathrm{P}=0.028)$ than who hadn't comorbidities. Participant who had nephropathic complication of diabetes were 6.45 more likely had poor glycemic control $(\mathrm{AOR}=6.45,95 \% \mathrm{CI}=1.967-5.497, \mathrm{P}=0.005)$ than those who had others complication (Table 4).

\section{Discussion}

Patients with diabetes have a 2-to-4-fold increase in the risk of both cardiovascular and cerebrovascular disease, resulting in an increased mortality rate among patients with diabetes compared to the general population [19]. The main goal of diabetes management is to ensure optimal glycemic control.Poorly controlled T2DM results in increased rates of micro and macrovascular diabetic complications which in turn lead to increased healthcare costs [20].

The present study revealed that the overall prevalence of poor glycemic control among type 2 diabetic patients was $60.7 \%$ were lower than study conducted in Military Hospital in Hodeidah 73.2\%,Ethiopia 64.72\%,Bangladesh 82\%,Saudi Arabia 74.9\%,Kuwait 78.8\% [21-25]. The differences was due to delay in the begging and intensification of unnecessarily and poor adherance to anti-diabetic treatments and also

Table 4. Logistic regression analysis of the association between independent variables and poor glycemic control among T2DM patients in Mettu Karl Referral Hospital Southwestern, Ethiopia, 2021

\begin{tabular}{|c|c|c|c|c|}
\hline Variables & Category & $n(\%)$ & AOR (95\% C.I) & P-value \\
\hline \multirow{2}{*}{ Age } & $\leq 40$ years & $56(45.9)$ & $2.98(1.089-2.023)$ & 0.034 \\
\hline & $>40$ years & $66(54.1)$ & \multicolumn{2}{|l|}{1} \\
\hline \multirow{2}{*}{ Sex } & Male & $67(54.9)$ & $1.96(1.043-1.848)$ & 0.078 \\
\hline & Female & $55(45.1)$ & \multicolumn{2}{|l|}{1} \\
\hline \multirow{4}{*}{ Educational status } & Uneducated & $45(36.9)$ & $1.75(1.957-3.649)$ & 0.009 \\
\hline & Primary & $39(32.0)$ & $1.01(1.968-1.967)$ & 0.869 \\
\hline & Secondary & $27(22.1)$ & $0.364(0.067-1.028)$ & 0.184 \\
\hline & Higher education & $11(9.0)$ & \multicolumn{2}{|l|}{1} \\
\hline \multirow{5}{*}{ Type of DM dr ugs } & Metformin & $41(33.6 .0)$ & $1.873(1.921-2.340)$ & 0.09 \\
\hline & $\begin{array}{l}\text { Glibenclamide and } \\
\text { metformin }\end{array}$ & 19(15.6) & $1.043(1.429-3.750)$ & 0.018 \\
\hline & Glibenclamide & $17(13.9)$ & $0.740(0.694-1.947)$ & 0.873 \\
\hline & $\begin{array}{l}\text { Metformin and NP H } \\
\text { insulin }\end{array}$ & $34(27.9)$ & $1.75(1.967-2.645)$ & 0.095 \\
\hline & $\begin{array}{l}\text { Metformin+ Insulin + } \\
\text { Glibenclamide }\end{array}$ & $11(9.0)$ & \multicolumn{2}{|l|}{1} \\
\hline \multirow{3}{*}{ Adherance } & Low & $56(45.9)$ & $2.68(1.764-4.928)$ & 0.002 \\
\hline & Moderate & $38(31.1)$ & $1.146(1.437-2.746)$ & 0.645 \\
\hline & High & $28(23.0)$ & \multicolumn{2}{|l|}{1} \\
\hline \multirow{4}{*}{ Social habit } & Cigarette smokers & $38(31.1)$ & $1.978(2.034-3.864)$ & 0.008 \\
\hline & Alcohol drinker & $32(26.2)$ & $1.34(1.564-2.853)$ & 0.07 \\
\hline & Khat chewing & $22(18.0)$ & $5.68(2.968-12.476)$ & 0.061 \\
\hline & None & $30(24.6)$ & \multicolumn{2}{|l|}{1} \\
\hline \multirow{2}{*}{ Comorbidity } & Yes & $67(54.9)$ & $2.5(1.967-5.497)$ & 0.028 \\
\hline & No & $55(45.1)$ & \multicolumn{2}{|l|}{1} \\
\hline \multirow{3}{*}{$\begin{array}{l}\text { Duration of tre } \\
\text { atment }\end{array}$} & $1-4$ years & $62(50.8)$ & $0.478(0.021-1.017)$ & 0.476 \\
\hline & $5-10$ years & $43(35.2)$ & $2.15(1.967-4.231)$ & 0.005 \\
\hline & $>10$ years & $17(13.9)$ & \multicolumn{2}{|l|}{1} \\
\hline \multirow{2}{*}{ Residency } & Urban & $50(41.0)$ & $1.254(1.694-2.078)$ & 0.045 \\
\hline & Rural & $72(59.0)$ & \multicolumn{2}{|l|}{1} \\
\hline \multirow{5}{*}{$\begin{array}{l}\text { Type of compli } \\
\text { cation }\end{array}$} & Retinopathy & $16(13.1)$ & $0.285(0.047-1.074)$ & 0.178 \\
\hline & Neuropathy & $17(13.9)$ & $1.476(1.967-2.863)$ & 0.710 \\
\hline & Nephropathy & $32(26.2)$ & $6.45(3.071-17.632)$ & 0.095 \\
\hline & $\begin{array}{l}\text { Cardiac complicatio } \\
\text { ns }\end{array}$ & $12(9.8)$ & $1.435(1.849-2.147)$ & 0.453 \\
\hline & None & $45(36.9)$ & \multicolumn{2}{|l|}{1} \\
\hline
\end{tabular}


Bereda G (2021) The incidence and predictors of poor glycemic control among adults with type 2 diabetes mellitus in ambulatory clinic of mettu karl referral hospital, Southwestern, Ethiopia: a prospective cross sectional study

include less life style modification which perhaps no health diet, and low physical exercise. Our study was in line with the study conducted in Middle East and the Horn of Africa 61.1\%, Shanan Gibe hospital 59.2\% $[26,27]$. This similarity was due to in sub-saharan Africa patients may not acquire their medication because they earn low monthly income and rural area residents patients had not got more education about disease burden and medication due to they far from social media and health center. The current study were higher than Saudi Arabia 50\%,china 50.3\%,Zimbabwe $58.2 \%$ [28-30]. This is because in our study diabetic patients were educated in the hospital how they use their medication somewhat.

In our study the incidence of poor glycemic control were observed in older ages > 40 years perhaps consistent with the study done in Bangladesh [24] which revealed that the prevalence of DM was more among old age group. This is because older adults were at high risk for the development of diabetic mellitus due to the combined effects of increasing insulin resistance and impaired pancreatic islet function with aging. And older agents are most vulnerable population, so diabetes increases the risk of falls, urinary incontinence, dementia, depression, vision and hearing loss. Besides, more likely to have functional limitations and report disability.

In our study uneducated type 2 diabetic patients had more poor glycemic control than primary, secondary, higher educational level were consistent with the study employed in Ethiopia [31] which displayed the significant difference of poor glycemic control was observed among illiterates than college/university graduates. This is because uneducated patients had no more hint on how and when to take the medication, how to monitor self-blood glucose sugar, how to take care for themselves and the no use balanced program of exercise and rest which help him/her keep blood sugar stable. Due lack comprehend they didn't use carbohydrate as snack when they feel weak.

The current study observed that males were at higher risk to developing poor glycemic control than females were inline with the study done in a Suburban Tertiary Hospital in North-Western Nigeria [32] which observed that males were at higher risk of having poor glycaemic control compared to females. The reason whose males store more fat in their bellies, plasma levels of low density lipoprotein (bad cholesterol) and triglycerides were high in males, and males had smoking cigarette, being overweight, avoiding physical activity.

The present showed 63.1\%patients had at least one complication. Here Nephropathy were the most commonly occurred diabetic complication and Neuropathy were the least occurred diabetic complication were higher than the study conducted in Tertiary Hospital in Northeast Ethiopia [33] which revealed that $59.7 \%$ of diabetic patients had at least one diabetic complication. The current survey were lower than the study conducted in Jimma, Ethiopia, where 83.0\%. Because diabetic nephropathy was a common complication of type I and type II diabetes. Overtime poorly control diabetes can cause damage to blood vessels clusters in the kidney that filter waste from the body.

The relative odds of poor glycemic control was 2.98-times $(\mathrm{AOR}=2.98,95 \% \mathrm{CI}=1.089-2.023, \mathrm{P}=0.034)$ higher among patients in the age $\leq 40$ years compared to the ages of greater than 40 years. Regarding educational status uneducated patients were 1.75 more likely had poor glycemic control $(\mathrm{AOR}=1.75,95 \% \mathrm{CI}=1.957-3.649$, $\mathrm{P}=0.009)$ than primary, secondary and higher educational status. Patients who take Glibenclamide and metformin drug regimen were 3.95 more likely had poor glycemic control $(\mathrm{AOR}=3.95,95 \% \mathrm{CI}=1.967-$ $9.645, \mathrm{P}=0.018)$ than those who taken others regimen. Low adherance were 2.68 more likely had poor glycemic control $(\mathrm{AOR}=2.68,95 \%$
$\mathrm{CI}=1.967-9.645, \mathrm{P}=0.002)$ than moderate and high adherance. Patients who whose cigarette smokers social habit were 1.49 more likely had poor glycemic control (AOR=1.49,95\%CI=1.967-9.645,P=0.008) than those who had others social habit. Patents who had comorbidities were 2.5 more likely have poor glycemic control $(\mathrm{AOR}=2.5,95 \% \mathrm{CI}=1.967$ 5.497, $\mathrm{P}=0.028)$ than who hadn't comorbidities. Participant who had nephropathic complication of diabetes were 6.45 more likely had poor glycemic control (AOR=6.45,95\%CI=1.967-5.497, $\mathrm{P}=0.005)$ than those who had others complication.

\section{Conclusion and Recommendation}

Our study investigated the prevalence of poor glycemic control among type 2 diabetic patients was high. About half of the patients were on anti-diabetic medication for between one to four years and slightly above one half of oral hypoglycemic agents were the most prescribed drug regimen. Above half of diabetic patients were had at least one comorbidities and had nephropathy diabetic complication. Hypertension was the most present comorbidities followed by renal disease. Age less than forty years, uneducated patients, glibenclamide and metformin drug regimen, low adherance, cigarette smokers, patients who had comorbidities, and patients who had nephropathic complication of diabetes were significantly factors associated with glycaemic control. Health care workers should have to advice the patients about life style modification and on how they take their medication.

\section{Acknowledgment}

We would like to extend our thanks to the data collectors and respondents.

\section{References}

1. Marathe PH, Gao HX, Close KL (2017) American diabetes association standards of medical care in diabetes. J Diabetes 40: 1-142.

2. Ogurtsova K, da Rocha Fernandes JD, Huang Y (2017) IDF Diabetes Atlas: Globa estimates for the prevalence of diabetes for 2015 and 2040. Diabetes Res Clin Pract 128: 40-50. [Crossref]

3. IDF (2013) Diabetes and impaired glucose tolerance. 6th ed. Brussels: Diabetes Atlas.

4. Whiting DR, Guariguata L, Weil C, Shaw J (2011) IDF diabetes atlas: global estimates of the prevalence of diabetes for 2011 and 2030. Diabetes Res Clin Pract 94: 311-321.

5. Sacks FM, Svetkey LP, Vollmer WM, Appel LJ, Bray GA (2001) Effects on blood pressure of reduced dietary sodium and the dietary approaches to stop hypertension (DA SH) diet. N Engl J Med 344: 3-10

6. Desse TA, Eshetie TC, Gudina EK (2015) Predictors and treatment outcome of Hyperglycemic emergencies at Jimma University Specialized Hospital, southwest. BMC Res Notes 8: 1-8.

7. Adham M, Froelicher ES, Batieha A, Ajlouni K (2010) Glycaemic control and its associated factor in type 2 diabetic patients in Amman, Jordan. East Mediterr Health $\mathrm{J}$ 16: 732-739. [Crossref]

8. Mohammad H, Amir N, Maryam H, Girish T, Surulivelrajan M (2018) Factors that correlate with poor glycemic control in type 2diabetes mellitus patients with complications. Osong Public Health Res Perspect 9: 167-174.

9. Alberti H, Boudriga N, Nabli M (2007) Primary care management of diabetes in a low/ middle income country: a multi-method, qualitative study of barriers and facilitato rs to care. BMC Fam Pract 8: 63.

10. Fauci AS (2008) Principles of Internal Medicine. Ed: 17th McGraw-Hill, New York, NY,USA.

11. Tadele E, Abrahaley M, Gebretsadik H, Getu K,Dagim A, Yerra R (2016) Factors associated with poor glycemic control in type 2 diabetic patients investigated at Ayder Referral Hospital, Mekelle, Ethiopia. Ijppr Human 6: 160-171.

12. Cheneke W, Suleman S, Yemane T, Abebe G (2016) Assessment of glycemic control using glycated hemoglobin among diabetic patients in Jimma University specialized hospita 1, Ethiopia. BMC Res Notes 9: 96. 
Bereda G (2021) The incidence and predictors of poor glycemic control among adults with type 2 diabetes mellitus in ambulatory clinic of mettu karl referral hospital, Southwestern, Ethiopia: a prospective cross sectional study

13. World Health Organization, Global Health Risks (2009) Mortality and Burden of Disease Attributable to Selected Major Risks, World Health Organization, Geneva.

14. Cho NH (2015) IDF Diabetes Atlas pp.1-142, Ed: $7^{\text {th }}$ International Diabetes Federation.

15. Temesgen F, Ermiyas A, Wongelawit K, Aderaw A, Angesom G (2018) Factors associated with glycemic control among diabetic adult outpatients in Northeast Ethiopia. BMC Res Notes 11: 316 .

16. Firouzi S, Barakatun-Nisak MY, Azmi KN (2015) Nutritional status, glycemic control and its associated risk factors among a sample of type 2 diabetic individuals, a pilot study. J Res Med Sci 20: 40-6.

17. Abebe SM, Berhane Y, Worku A, Alemu S, Mesfin N (2015) Level of sustained glycemic control and associated factors among patients with diabetes mellitus in Ethiopia:a hospital-based cross-sectional study. Diabet Metab Synd Obes 8: 65-71.

18. Colagiuri S, Lee CM, Wong TY, Balkau B, Shaw JE (2011) Glycemic thresholds for diabetes-specific retinopathy: implications for diagnostic criteria for diabetes. Diabet Care 34: 145-150.

19. Team DMG (2014) Management of Type 2 Diabetes Mellitus. In: Management U editor

20. Koro CE, Bowlin SJ, Bourgeois N, Fedder DO (2004) Glycaemic control from1988 to 2000 among U.S. adults diagnosed with type 2 diabetes: a preliminary report. Diabetes Care 27: 17-2019.

21. Sultan AM Saghir (2019) Factors associated with poor glycemic control among type-2 diabetes mellitus patients in Yemen. Tropical Journal of Pharmaceutical Research 18: 1539-1546.

22. Agalu A Abejew, Zeleke A Belay, Woldie M Kerie (2015) Diabetic Complications among Adult Diabetic Patients of a Tertiary Hospital in Northeast Ethiopia. Advances in Public Health 7.

23. Afroz A, Ali L, Karim MN, Alramadan MJ, Alam K, et al. (2019) Glycaemic Control for People with Type 2 Diabetes Mellitus in Bangladesh -An urgent need for optimization of management plan. Sci Rep 9: 10248.
24. Alshenghiti AM, Alsadran FF, Alzahrani RA, Assiri I (2016) Sleep quality among type 2 Saudi diabetics. Med J Cairo Uni 167-171.

25. Al-Ibrahim AA (2012) Factors Associated with Compliance to Diabetes Self Care Behaviors and Glycemic Control Among Kuwaiti People with Type 2 Diabetes. University of Maryland 5: 1314-1328.

26. Sulaiman AM, Saghir SA, Al-Hassan FM, Yusoff NM, Zaki AH (2013) Molecular charact erization of glucose-6-phosphate dehydrogenase deficiency in a university community in Malaysia. Trop J Pharm Res 12: 363-367.

27. Miteku YD, Alemu DT (2017) Glycemic control and associated factors among type 2 diabetic patients at shanan gibe hospital,southwest ethiopia. BMC Res Notes 10: 597.

28. Almutairi MA, Said SM, Zainuddin H (2013) Predictors of Poor Glycemic Control among Type two Diabetic Patients. Am J Med Sci 3: 17-21.

29. Li J, Chattopadhyay K, Xu M, Chen Y, Hu F, et al. (2018) Glycaemic control in type 2 diabetes patients and its predictors: a retrospective database study at a tertiary care diabetes centre in Ningbo, China. BMJ Open 8: e019697. [Crossref]

30. Chirombe M, Ngara B, Chibvongodze R, Charuka V (2018) Glucose Control in Diabetic Patients Attending Parirenyatwa Group of Hospitals in Zimbabwe. The Open Clinical Biochemistry Journal 19: 9-12.

31. Tekalegn Y, Addissie A, Kebede T, Ayele W (2018) Magnitude of glycemic control and its associated factors among patients with type 2diabetes at Tikur Anbessa Specialized Hospital, Addis Ababa, Ethiopia. PLoSONE 13: e0193442. [Crossref]

32. Yakubu A (2020) Determinants of Poor Glycaemic Control among Type 2 Diabetic Patients at a Suburban Tertiary Hospital in North-Western Nigeria. International Jour nal of Science and Healthcare Research 5: 4.

33. Alebachew M Woldu (2014) Factors Associated with Poor Glycemic Control among Patients with Type 2 Diabetes Mellitus in Ambo Hospital, Ambo, Ethiopia. Endocrin ol Metab Synd 3: 4.

Copyright: $(92021$ Bereda G. This is an open-access article distributed under the terms of the Creative Commons Attribution License, which permits unrestricted use, distribution, and reproduction in any medium, provided the original author and source are credited. 